\title{
Eye Diseases and Impaired Vision as Possible Risk Factors for Recurrent Falls in the Aged: A Systematic Review
}

\author{
Liisa Salonen $^{1,2}$ and Sirkka-Liisa Kivelä ${ }^{1,3,4,5}$ \\ ${ }^{1}$ Department of Family Medicine, University of Turku, Lemminkäisenkatu 1, 20014 Turku, Finland \\ ${ }^{2}$ The Health Care Center of Parainen, Vapparintie 15 A, 21600 Parainen, Finland \\ ${ }^{3}$ Unit of Family Medicine, Turku University Hospital, PL 52, 20521 Turku, Finland \\ ${ }^{4}$ Satakunta Hospital District, Sairaalantie 3, 28500 Pori, Finland \\ ${ }^{5}$ Division on Social Pharmacy, University of Helsinki, Viikinkaari 9, 00014 University of Helsinki, Finland
}

Correspondence should be addressed to Liisa Salonen, liisa.salonen@utu.fi

Received 9 February 2012; Revised 21 May 2012; Accepted 3 June 2012

Academic Editor: Arnold B. Mitnitski

Copyright ( 2012 L. Salonen and S.-L. Kivelä. This is an open access article distributed under the Creative Commons Attribution License, which permits unrestricted use, distribution, and reproduction in any medium, provided the original work is properly cited.

\begin{abstract}
Background. Recurrent falls are common among the aged. Vision is needed in maintaining balance, and impaired vision may be an intrinsic risk factor of recurrent falls. The aim was to perform a systematic review about the relationships between eye diseases or impaired vision and the risk of recurrent falls in the aged. Material and Methods. MEDLINE and CINAHL databases were searched in order to find longitudinal epidemiological studies about the associations between eye diseases or impaired vision and the risk of recurrent falls. Altogether 19 studies were found. A qualitative systematic analysis of these studies was performed. Results and Conclusions. The evidence about poor depth perception/stereoacuity and poor low-contrast visual acuity as risk factors of recurrent falls is quite convincing. Discrepant vision, a decrease in visual acuity, and loss of visual field may be risk factors, but more studies are needed. The results concerning the relationships between poor visual acuity and poor contrast sensitivity and the risk of recurrent falls are controversial. More studies about the relationships between different measures of vision and the risk of recurrent falls are needed before final conclusions about poor vision as a risk factor for recurrent falling can be done.
\end{abstract}

\section{Introduction}

Falls are common among the aged. One-third of communitydwelling people over the age of 65 years fall at least once a year [1-5]. The aged living in long-term institutions or in sheltered housing experience more falls than the homedwelling aged [4]. Falls cause remarkable costs to the health care, and they may lead to long-term disabilities in the aged. Roughly $40 \%$ of serious falls lead to hospital admission, and $30-40 \%$ of the fallers admitted to hospitals are later transferred to nursing homes [6]. There are many reasons to develop prevention of falls.

Falls may be classified in several ways. A common classification categorizes falls into three groups: falls that result from interference with the base of support (trips, slips), falls which result from externally applied push or self-induced displacement during bending, reaching, turning, or transfer, and falls which result from a physiological event that disrupts posture control mechanisms. Falls belonging to the first and second categories are usually accidental ones, and the person does not fall recurrently. Falls resulting from a physiological event are usually recurrent ones: the person falls several times a year [7].

Visual functioning, the ability to detect surroundings, is needed for posture control. Impaired vision may, thus, be a risk factor for falls, especially for recurrent falls. In preventing recurrent falls we need to know the specific features of vision that are risk factors for the recurrence. The development of recurrent falls prevention strategies should be based on the use of practical and exact tests of these risk factors. We decided to perform a systematic review about the relationships between eye diseases or impaired vision and the risk of recurrent falls in order to find the specific features of vision which increase the risk for falling recurrently. 
TAble 1: Search strategies.

\begin{tabular}{|c|c|}
\hline $\begin{array}{l}\text { Search identification } \\
\text { number }\end{array}$ & Search terms \\
\hline \multicolumn{2}{|r|}{ Search strategy of the first search } \\
\hline S1 & Vision/or exp eye diseases/or exp vision disorders/ \\
\hline S2 & $\begin{array}{l}\text { ( }(v i s u a l \$ \text { or vision or sight or eyesight or eye } \$ 1 \text { or ocular) adj (impairment } \$ \text { or disorder } \$ \text { or disease } \$ \text { or deficit } \$ \\
\text { or problem } \$ \text { or disturb } \$ \text { or lower } \$ \text { or low or loss or reduc } \$ \text { or decreas } \$ \text { or weak } \$ \text { or decay } \$ \text { or diminish } \$ \text { or fail } \$ \\
\text { or handicap } \$ \text { or hindrance } \$ \text { or damage } \$ \text { or injur } \$)) \text { tw. }\end{array}$ \\
\hline S3 & $\mathrm{S} 1$ or S2 \\
\hline S4 & Accidental falls/or (falling $\$$ or fall $\$ 1$ ). ti. \\
\hline S5 & $\mathrm{S} 3$ and $\mathrm{S} 4$ \\
\hline S6 & Limit 5 to ("aged ( 80 and over)" or aged $<65$ to 79 years $>$ or "aged $<80$ and over $>$ " or all aged ( 65 and over)") \\
\hline S7 & Aging/or exp Aged/or (aging or ageing or elder\$ or geriatr\$ or gerontol\$ or aged).tw. \\
\hline S8 & S5 and S7 \\
\hline S9 & S6 or S8 \\
\hline S10 & Remove duplicates from S9 \\
\hline S11 & $\begin{array}{l}\text { (predict\$ or hazard } \$ \text { or risk\$ or progno } \$ \text { or recurrent } \$ \text { or repeat } \$ \text { or repetit } \$ \text { or frequen } \$ \text { or continu } \$ \text { or } \\
\text { iterative). mp. }\end{array}$ \\
\hline S12 & S10 and S11 \\
\hline S13 & Limit S12 to abstracts \\
\hline S14 & Limit S13 to English \\
\hline S15 & Limit S14 to yr = “1980-2008” \\
\hline \multicolumn{2}{|r|}{ Search strategy of the second and third searches in CINAHL } \\
\hline S1 & (MH “Vision+") or (MH “Vision Disorders+”) \\
\hline S2 & $\begin{array}{l}\text { (Visual* or vision or sight or eyesight or eye or eyes or ocular) and (impairment* or disorder* or disease* or } \\
\text { deficit* or problem* or disturb* or low or loss or reduc* or decreas* or weak* or decay* or diminish* or fail* } \\
\text { or handicap* or hindrance* or damage* or injur*) }\end{array}$ \\
\hline S3 & $\mathrm{S} 1$ or S2 \\
\hline S4 & (MH "Accidental Falls") or falling* or fall or falls \\
\hline S5 & S3 and S4 \\
\hline \multirow{2}{*}{ S6 } & S3 and S4 \\
\hline & Search options: Limiters-Age Groups: Aged: $65+$ years \\
\hline S7 & MH “Aging+” or MH “Aged+” or (aging or ageing or elder* or geriatr* or gerontol* or senior*) \\
\hline S8 & S5 and S7 \\
\hline S9 & S6 or S8 \\
\hline \multirow{2}{*}{ S10 } & $\mathrm{S} 6$ or S8 \\
\hline & $\begin{array}{l}\text { Search options: Limiters-Abstract Available; Publication Year from: 1980-2010 (the second search), } \\
\text { 5/2010-5/2012 (the third search); English Language: Exclude MEDLINE records }\end{array}$ \\
\hline
\end{tabular}

\section{Material and Methods}

2.1. Search Strategy and Selection Criteria. Updated MEDLINE (1980-2/2008) and CINAHL (1980-2/2008) databases were searched from the Ovid database on February 20th, 2008 by using the strategy shown in Table 1. A second search in the MEDLINE and CINAHL databases was run on the 6 th of May, 2010. The search strategy to MEDLINE was exactly the same as two years before, but the publication interval was altered to be 1980-2010. Because the Ovid database did not exist anymore, CINAHL was searched by a comparable strategy shown in Table 1. The third search to both databases was done on the 27th of May, 2012 with the strategies used in 2010. The only change done was that the publication interval was changed to be 5/2010-5/2012.
The language was restricted, and only English articles were taken into account. From the first search, critical reviews and longitudinal and cross-sectional studies were accepted though only retrospective or prospective longitudinal studies were included in this review. From the second and third searches, only retrospective or prospective longitudinal studies were accepted.

A total of 141 citations were identified from the first search in MEDLINE and CINAHL (Figure 1). 141 citations included 2 articles twice. Both writers read through the titles.

According to their titles, 42 articles considered the relationships between eye diseases or impaired vision and the risk of falls. 43 articles were excluded because there were not retrospective or prospective longitudinal studies or critical reviews. 54 articles were excluded because they did not 


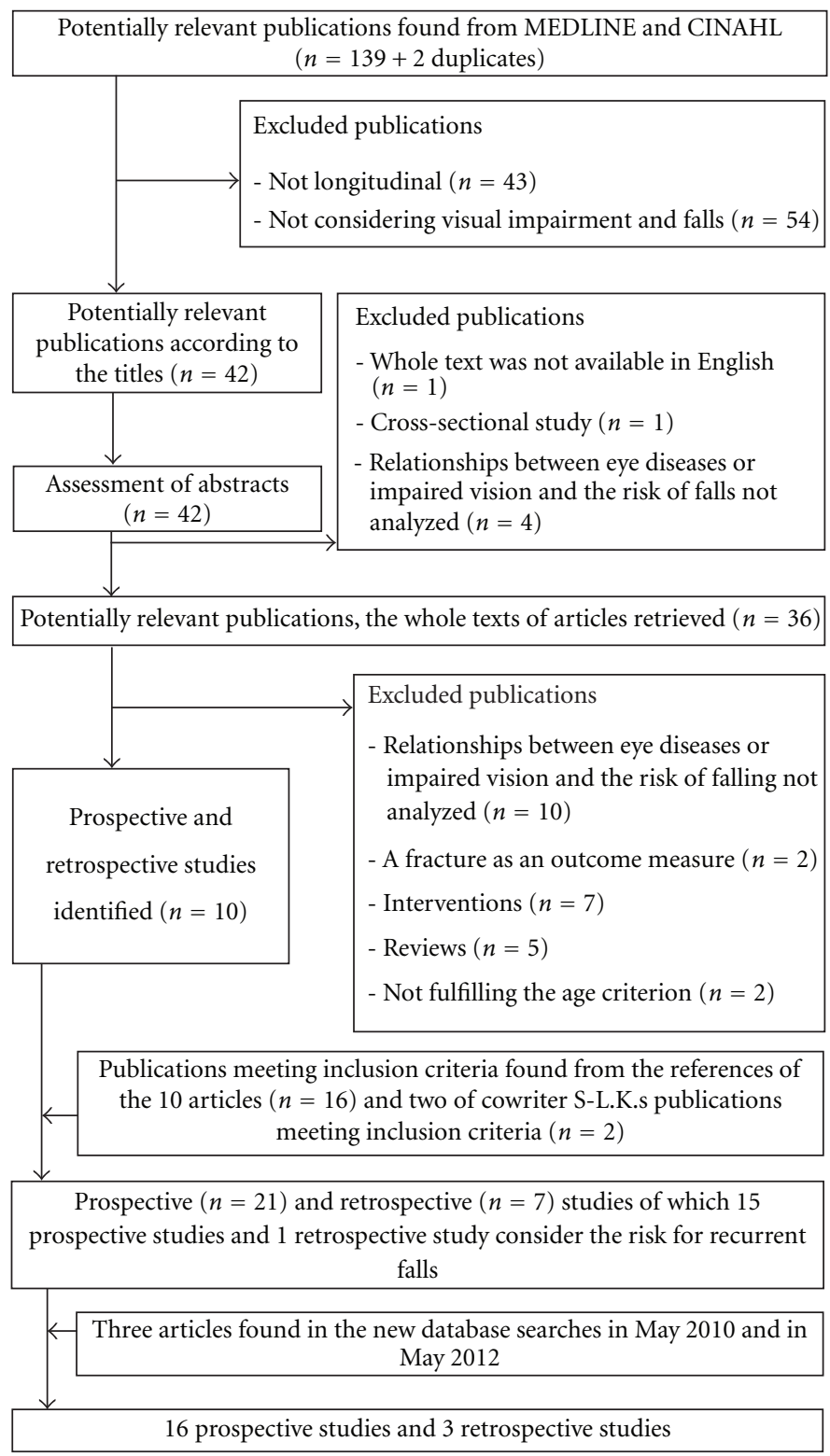

FIgURE 1: Flow chart.

consider impaired vision/eye diseases or falling. Abstracts of chosen 42 articles were read by one author (L. M. Salonen), who selected prospective and retrospective studies and critical reviews about relationships between eye diseases or impaired vision and the risk of falls to be read. Altogether six articles were excluded in this phase because they were crosssectional studies $(n=1)$ or did not consider relationships between eye diseases or impaired vision and the risk of falling $(n=4)$ or were not published in English $(n=1)$.

The whole texts of the remaining 36 articles were read by the same author (L. M. Salonen). In this phase, 24 articles were excluded because they were reviews $(n=5)$ considered interventions $(n=7)$ did not analyze relationships between eye diseases or impaired vision and the risk of falling $(n=$ $10)$, or used a fracture as an outcome measure $(n=2)$. Only studies with mean age of the population over 65 years, or with the youngest participants older than 60 years if the mean age was not mentioned, were included. Two studies failed to meet the age criterion.

The reference lists of 10 original studies identified in this phase were checked by both authors, and additional 16 original studies meeting the above inclusion criteria were found and included in the material. In addition, two studies performed by one of the authors (S. L. Kivelä) of this paper were included in the material because they met the inclusion criteria, although they were not identified in the search.

These 28 studies were classified according to their outcome variables into those considering recurrent falls $(n=$ 16) and those considering nonrecurrent falls $(n=12)$.

157 titles were achieved from MEDLINE and 72 from CINAHL in the second search run. Both writers of this paper read the abstracts to find additional articles considering 
impaired vision as a risk factor for recurrent falls. Only one new report was found. On the third search run, 35 titles were found from MEDLINE and 10 titles from CINAHL. Abstracts of all articles were read by both writers. Based on abstracts, 13 articles were possibly suitable to this literature review and the whole texts of these articles were read by $\mathrm{L}$. M. Salonen. Two new articles fulfilled the inclusion criteria.

The studies about the relationships between eye diseases or impaired vision and the risk of recurrent falls formed the material of this systematic review. The final material consisted of 16 prospective studies and 3 retrospective studies.

The studies were classified according to the design (prospective/retrospective), measure of vision (objective near visual acuity, objective distant visual acuity, low contrast visual acuity, high-contrast visual acuity, distant contrast sensitivity, near contrast sensitivity, stereoacuity, visual field, perception of verticality, discrepant vision, subjective visual acuity, self-reported vision worsening, and eye diseases: glaucoma, cataract, and retinal diseases) used as a potential risk factor, and material (community-dwelling population, unselected population, intermediate care residents, and institutionalized population).

\section{Results}

\subsection{Prospective Studies}

3.1.1. Unselected Populations. The potential risk factors taken into account in one report [8] (Table 2) considering an unselected population consisting of both home-dwelling and institutionalized participants were low contrast sensitivity and subjective poor vision. The results were adjusted for age, gender, and health variables.

Low contrast sensitivity was significantly related to the risk of recurrent falls, but subjective poor vision was not.

\subsubsection{Community-Dwelling Populations. Ten prospective} reports were found about relationships between impaired vision or eye diseases and the risk of recurrent falls in community-dwelling populations [3, 5, 9-16] (Table 2). Two reports concerned the same cohort of LASA $[5,14]$, and two reports concerned The Study of Osteoporotic Fractures in which all participants were women $[10,11]$.

Five reports considered poor visual acuity as a potential risk factor for recurrent falls $[3,9,10,13,16]$. In addition, in the LASA reports, subjective poor visual acuity (determined by asking if participants were capable of recognizing faces from 4 meters distance) was considered as a potential risk factor $[5,14]$. Other potential risk factors considered were low contrast visual acuity $[3,13]$, change in visual acuity [11], poor distant contrast sensitivity $[3,9,10,13,16]$, poor near contrast sensitivity [13], poor depth perception/stereoacuity $[13,16]$, visual field loss $[10,12,13,16]$, discrepant vision [9], and eye diseases such as glaucoma, cataract, or retinal diseases $[11,15]$.

In eight reports $[5,10-16]$, risk ratios were calculated and in five of these studies $[10-13,16]$ they were adjusted for several confounders. An analysis of variance with adjustment of age was used in two studies [3, 9].
Poor visual acuity was related to the risk of falling recurrently in one [9] of five studies. Subjective poor vision [5, 14] and reduced low contrast visual acuity $[3,13]$ were found to be risk factors in both studies in which they were measured and a reduction in visual acuity was related to the risk in the study using this criterion [11].

Poor stereoacuity and poor depth perception were detected to be significant risk factors in both studies in which they were measured $[13,16]$. Visual field loss was related to the risk of recurrent falls in two reports $[10,12]$ out of four, and poor contrast sensitivity was related to the risk of recurrent falls in three reports $[3,9,13]$ out of five. Near contrast sensitivity was measured separately in one study, and it was not related to the risk of recurrent falls [13]. One [15] out of two reports concerning eye diseases as potential risk factors found a positive association between eye diseases and recurrent falling. Discrepant vision was a significant risk factor for recurrent falls [9].

3.1.3. Residents in Intermediate Care. The search produced four studies (Table 2) about relationships between impaired vision or eye diseases and the risk of recurrent falls among the residents in intermediate care: two studies in a hostel for the aged in Australia [17, 18], one study in intermediate care facilities in the USA [19], and one study in homes and apartments for the aged in The Netherlands [20].

The potential risk factors measured in these studies were decreased visual acuity [17-19], poor self-reported visual acuity [20], poor contrast sensitivity [18], visual field loss [17], and eye diseases [17]. Risk ratios were adjusted for age and sex in one study [20] and unadjusted in two studies $[17,19]$, and an analysis of variance adjusted for age was performed in one study [18].

Poor visual acuity was related to the risk for recurrent falling in two $[17,19]$ out of three studies and reduced contrast sensitivity was a significant risk factor in the only report using this measure [18]. Poor self-reported visual acuity, visual field loss, and eye diseases were not related to the risk of falling recurrently $[17,20]$.

3.1.4. Institutionalized Populations. The results adjusted for confounders by the logistic regression analysis in the study in the aged in long-term institutional care [21] showed that the self-reported diagnosis of any eye disease was independently related to the risk of recurrent falls (Table 2).

\subsection{Retrospective Studies}

3.2.1. Community-Dwelling Populations. 3 retrospective studies [22-24] (Table 2) analyzed relationships between impaired vision or eye diseases and the risk of recurrent falls in a community-dwelling population. The potential risk factors measured in these studies were reduced visual acuity $[22,23]$, poor subjective visual acuity $[22,24]$, poor contrast sensitivity [22], loss of visual field [22], and eye diseases [22]. The results adjusted for age, gender and potential health variables showed reduced visual acuity $[22,23]$, poor contrast sensitivity [22], and loss of visual 


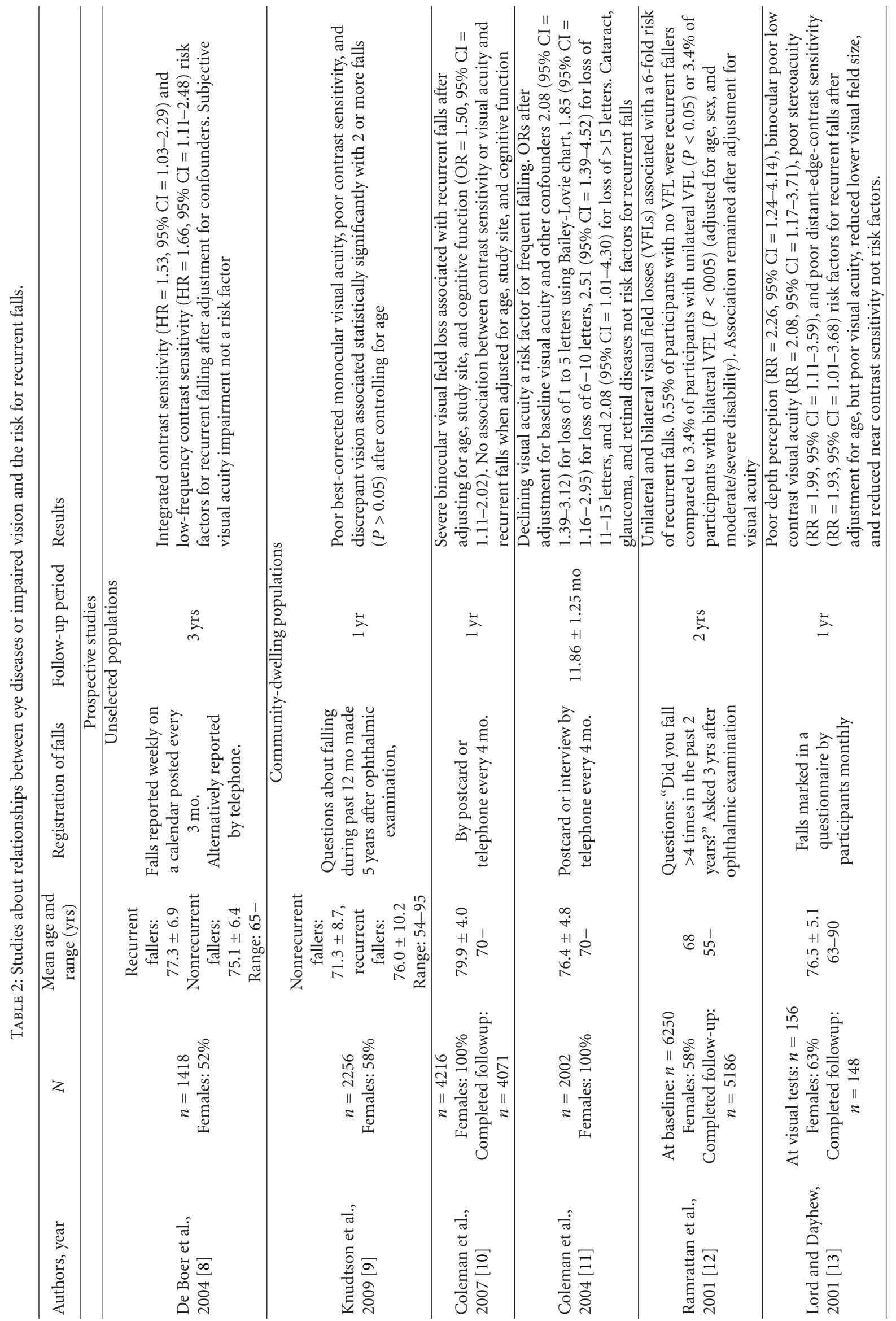




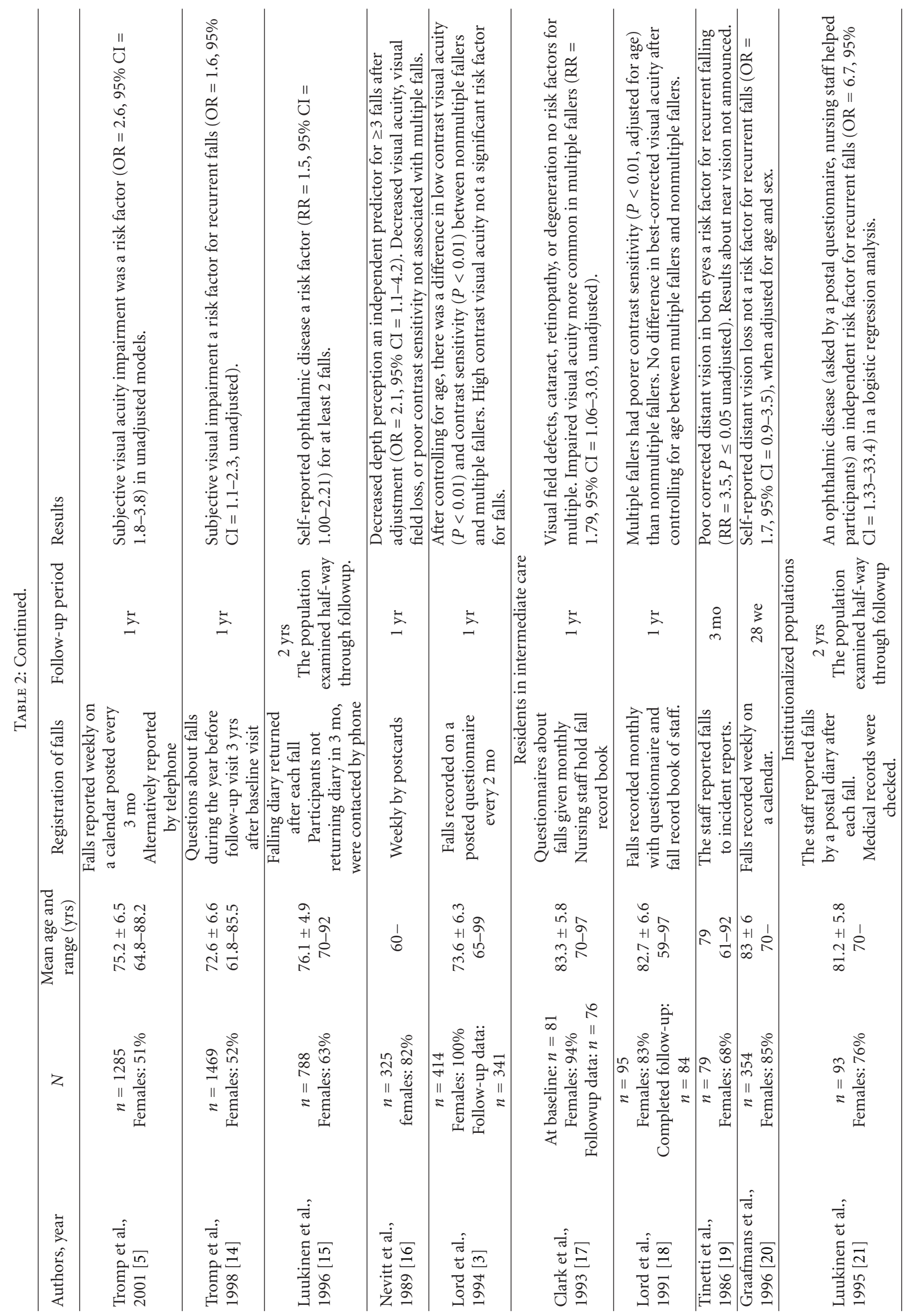




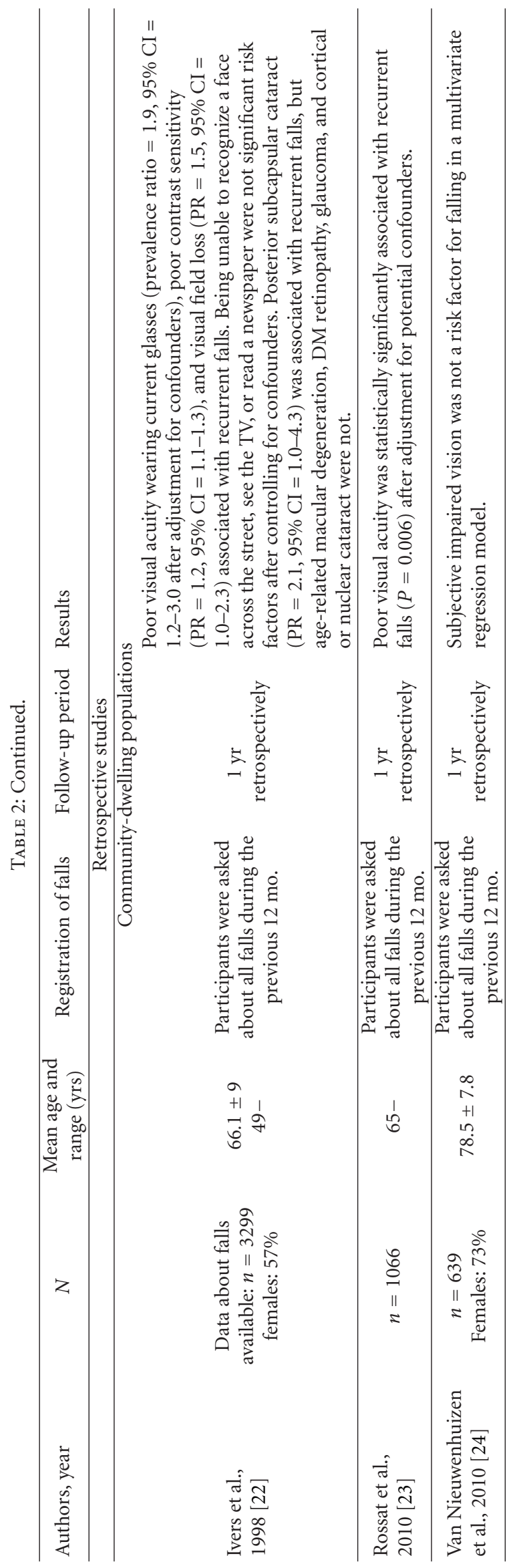


field [22] to be related to the risk of recurrent falls. Posterior subcapsular cataract was related to the risk, but other types of cataract, glaucoma, age-related macular regeneration, diabetic retinopathy, and subjective impaired visual acuity were not related to the risk $[22,24]$.

\section{Discussion}

Relationships between impaired vision or eye diseases and the risk of recurrent falls among the aged have been studied in a fairly large number of prospective and retrospective studies. Some studies have been done in unselected or community-dwelling populations, but the populations in some studies are selected, for example, the aged living in intermediate care facilities. Unselected populations are the most valuable materials for epidemiologic studies. For the qualitative analysis of this systematic review, the studies were divided into subgroups according to their materials, because differences in the selectivity of populations cause problems in the interpretation of the results.

The majority $(n=16)$ of the reports were prospective ones, and three studies used retrospective design. The studies using retrospective design were taken into account, although conclusions from their results must be done more critically than those from the results of prospective ones. By using a retrospective design, it is difficult to determine if certain identified risk factors such as poor functional abilities are consequences of previous falls. However, this is not a major problem when concentrating on impaired vision as a potential risk factor, because falls seldom result in visual impairment.

Other variables previously found to be related to the risk of recurrent falls were adjusted in a number of studies. The results of the studies which did not take into account these confounding variables are less valuable than the ones in which multivariate analyses were performed.

Registration of falls varied between the studies causing problems in assessing the reliability of the results and comparing the results with each other. A prospective followup with a fall record form is regarded as the most reliable method. Participants filled in fall record forms or reported falls regularly either by making written notes or by telephone in 13 prospective studies. Registration of falls by asking retrospectively is quite unreliable. Cummings et al. [25] studied 304 ambulatory persons in a prospective study and noticed that when asking participants one year after the baseline examination if they had fallen at least once during the previous year, $13 \%$ of fallers did not remember a fall event. If participants were asked one year after the baseline examination about falls during most recent 3 months, $32 \%$ of fallers denied falling. The proposed explanation is that participants remembered the baseline examination and therefore they could recall if a fall had happened before or after the examination.

The materials of a majority $(n=7)$ of prospective studies and the materials of two retrospective studies performed in unselected or community-dwelling populations include some thousands of participants. In five studies done in unselected or community-dwelling populations the number of participants was less than one thousand. The followup periods in studies done in unselected or communitydwelling populations lasted at least one year. It seems likely that even weaker risk factors were detected in these studies.

The numbers of participants in studies performed in intermediate care or in long-term institutions were quite small $(n=79-354)$. The follow-up periods lasted only three months or seven months in two studies, and three studies used a follow-up of one year or two years. We suggest that only stronger risk factors were detected among these selected populations.

The studies differed in methods which were used to assess visual acuity and other specific features of vision. These differences caused problems in comparing the results and in drawing conclusions. Objective methods were used in 11 prospective studies, and 5 prospective studies were based on only subjective experiences of poor vision or on self-reported diagnosis of an eye disease. Two retrospective studies utilized objective measures and one was based on subjective experience of poor vision. Self-reported eye disease diagnoses are not very reliable measures. The methods to measure visual acuity differed between the studies. Binocular visual acuity, which is a more relevant measure than monocular visual acuity, was measured in most of the studies. Objective measurements are usually done in standardized conditions (e.g., lighting), which differ from daily living conditions. Subjective assessments are based on persons' experiences in their normal living surroundings. Therefore, a subjective assessment of vision may be quite valuable and informative. However, the question about subjective vision can be understood in a different way by different participants.

Five prospective studies done in unselected or community-dwelling populations with the adjustment of multiple confounders (more than gender or age) were found $[8,10-$ $12,16]$. Both depth perception [16] and change in visual acuity [11] were measured in one study in which they proved to be significant risk factors. Visual field loss was a significant risk factor in two $[10,12]$ out of three studies. Poor contrast sensitivity was related to the risk of recurrent falls in one [8] out of three studies. Subjective poor vision [8] and selfreported eye diseases [11] were not found to be risk factors in the study in which they were measured.

Three prospective studies done in community-dwelling populations adjusting results only for age $[3,9,13]$ were found. Two studies $[3,13]$ found reduced low contrast visual acuity, and all three studies found reduced contrast sensitivity to be risk factors for recurrent falling. Streoacuity was a significant risk factor in the study in which it was measured [13].

Three prospective studies $[5,14,15]$ done in communitydwelling populations without an adjustment of results found subjective poor vision to be related to the risk of recurrent falls. Self-reported diagnosis of an eye disease was a significant risk factor according to one study [15].

Two retrospective studies $[22,23]$ done in a communitydwelling populations with results adjusted for several confounders found poor visual acuity to be related to the risk of recurrent falls. Poor contrast sensitivity, loss of visual field, 
and posterior subcapsular cataract were risk factors to recurrent falls in one study [22].

One prospective study done in an institutionalized population found a self-reported eye disease to be a significant risk factor for recurrent falls after adjustment for several confounders [21]. Two prospective studies [18, 20] done in intermediate care used an adjustment only for age and/or sex and only reduced contrast sensitivity was related to risk of falling in one of these studies. Two prospective studies $[17,19]$ done in intermediate care without adjustment of the results found poor visual acuity to be a risk factor for recurrent falling.

\section{Conclusions}

The evidence about poor depth perception/stereoacuity and poor low contrast visual acuity as risk factors for recurrent falls is quite strong. Discrepant vision, a decrease in visual acuity within a relatively short time and loss of visual field may be risk factors, but more studies are needed. The results about the relationships between poor visual acuity and poor contrast sensitivity and the risk of recurrent falls are controversial.

More studies about the relationships between different measures of vision and the risk of recurrent falls are needed, because the results of the studies reviewed in this paper are partly controversial. Measures of functional vision which are easily determined in primary health care should be developed, and these measures should be included in these studies. The available results suggest that the measurement of vision should be included in prevention of future falls among the aged who have sustained an injurious fall and in health promotion programs for the aged.

\section{Acknowledgment}

The authors thank Heikki Forsvik, M.D., docent, for comments on the paper.

\section{References}

[1] M. E. Tinetti, M. Speechley, and S. F. Ginter, "Risk factors for falls among elderly persons living in the community," New England Journal of Medicine, vol. 319, no. 26, pp. 1701-1707, 1988.

[2] A. J. Campbell, M. J. Borrie, and G. F. Spears, "Risk factors for falls in a community-based prospective study of people of 70 years and older," Journals of Gerontology, vol. 44, no. 4, pp. M112-M117, 1989.

[3] S. R. Lord, J. A. Ward, P. Williams, and K. J. Anstey, "Physiological factors associated with falls in older communitydwelling women," Journal of the American Geriatrics Society, vol. 42, no. 10, pp. 1110-1117, 1994.

[4] H. Luukinen, K. Koski, L. Hiltunen, and S. L. Kivelä, "Incidence rate of falls in an aged population in northern Finland," Journal of Clinical Epidemiology, vol. 47, no. 8, pp. 843-850, 1994.

[5] A. M. Tromp, S. M. F. Pluijm, J. H. Smit, D. J. H. Deeg, L. M. Bouter, and P. Lips, "Fall-risk screening test: a prospective study on predictors for falls in community-dwelling elderly,"
Journal of Clinical Epidemiology, vol. 54, no. 8, pp. 837-844, 2001.

[6] R. W. Sattin, D. A. Lambert Huber, C. A. DeVito et al., "The incidence of fall injury events among the elderly in a defined population," American Journal of Epidemiology, vol. 131, no. 6, pp. 1028-1037, 1990.

[7] A. K. Topper, B. E. Maki, and P. J. Holliday, "Are activitybased assessments of balance and gait in the elderly predictive of risk of falling and/or type of fall?" Journal of the American Geriatrics Society, vol. 41, no. 5, pp. 479-487, 1993.

[8] M. R. De Boer, S. M. F. Pluijm, P. Lips et al., "Different aspects of visual impairment as risk factors for falls and fractures in older men and women," Journal of Bone and Mineral Research, vol. 19, no. 9, pp. 1539-1547, 2004.

[9] M. D. Knudtson, B. E. K. Klein, and R. Klein, "Biomarkers of aging and falling: the Beaver Dam eye study," Archives of Gerontology and Geriatrics, vol. 49, no. 1, pp. 22-26, 2009.

[10] A. L. Coleman, S. R. Cummings, F. Yu et al., "Binocular visual-field loss increases the risk of future falls in older white women," Journal of the American Geriatrics Society, vol. 55, no. 3, pp. 357-364, 2007.

[11] A. L. Coleman, K. Stone, S. K. Ewing et al., "Higher risk of multiple falls among elderly women who lose visual acuity," Ophthalmology, vol. 111, no. 5, pp. 857-862, 2004.

[12] R. S. Ramrattan, R. C. W. Wolfs, S. Panda-Jonas et al., "Prevalence and causes of visual field loss in the elderly and associations with impairment in daily functioning: the Rotterdam Study," Archives of Ophthalmology, vol. 119, no. 12, pp. 1788-1794, 2001.

[13] S. R. Lord and J. Dayhew, "Visual risk factors for falls in older people," Journal of the American Geriatrics Society, vol. 49, no. 5, pp. 508-515, 2001.

[14] A. M. Tromp, J. H. Smit, D. J. H. Deeg, L. M. Bouter, and P. Lips, "Predictors for falls and fractures in the longitudinal aging study Amsterdam," Journal of Bone and Mineral Research, vol. 13, no. 12, pp. 1932-1939, 1998.

[15] H. Luukinen, K. Koski, S. L. Kivela, and P. Laippala, "Social status, life changes, housing conditions, health, functional abilities and life-style as risk factors for recurrent falls among the home-dwelling elderly," Public Health, vol. 110, no. 2, pp. 115-118, 1996.

[16] M. C. Nevitt, S. R. Cummings, S. Kidd, and D. Black, "Risk factors for recurrent nonsyncopal falls. A prospective study," Journal of the American Medical Association, vol. 261, no. 18, pp. 2663-2668, 1989.

[17] R. D. Clark, S. R. Lord, and I. W. Webster, "Clinical parameters associated with falls in an elderly population," Gerontology, vol. 39, no. 2, pp. 117-123, 1993.

[18] S. R. Lord, R. D. Clark, and I. W. Webster, "Physiological factors associated with falls in an elderly population," Journal of the American Geriatrics Society, vol. 39, no. 12, pp. 11941200, 1991.

[19] M. E. Tinetti, T. Franklin Williams, and R. Mayewski, "Fall risk index for elderly patients based on number of chronic disabilities," American Journal of Medicine, vol. 80, no. 3, pp. 429-434, 1986.

[20] W. C. Graafmans, M. E. Ooms, H. M. A. Hofstee, P. D. Bezemer, L. M. Bouter, and P. Lips, "Falls in the elderly: a prospective study of risk factors and risk profiles," American Journal of Epidemiology, vol. 143, no. 11, pp. 1129-1136, 1996.

[21] H. Luukinen, K. Koski, P. Laippala, and S. L. Kivela, "Risk factors for recurrent falls in the elderly in long-term institutional care," Public Health, vol. 109, no. 1, pp. 57-65, 1995. 
[22] R. Q. Ivers, R. G. Cumming, P. Mitchell, and K. Attebo, "Visual impairment and falls in older adults: the blue mountains eye study," Journal of the American Geriatrics Society, vol. 46, no. 1, pp. 58-64, 1998.

[23] A. Rossat, B. Fantino, C. Nitenberg et al., "Risk factors for falling in community-dwelling older adults: which of them are associated with the recurrence of falls?" Journal of Nutrition, Health and Aging, vol. 14, no. 9, pp. 787-791, 2010.

[24] R. C. Van Nieuwenhuizen, N. Van Dijk, F. G. Van Breda et al., "Assessing the prevalence of modifiable risk factors in older patients visiting an ED due to a fall using the CAREFALL Triage Instrument," American Journal of Emergency Medicine, vol. 28, no. 9, pp. 994-1001, 2010.

[25] S. R. Cummings, M. C. Nevitt, and S. Kidd, "Forgetting falls. The limited accuracy of recall of falls in the elderly," Journal of the American Geriatrics Society, vol. 36, no. 7, pp. 613-616, 1988. 


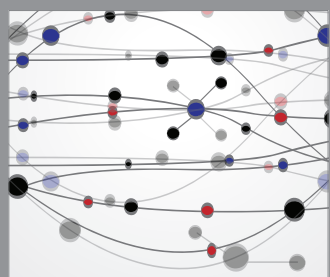

The Scientific World Journal
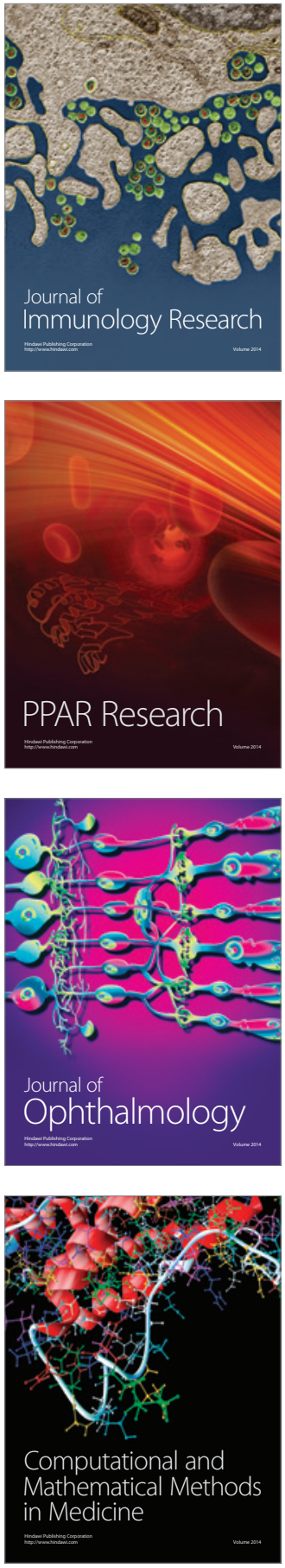

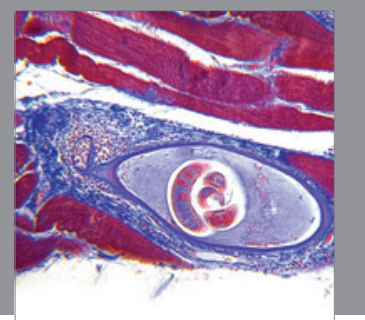

Gastroenterology

Research and Practice
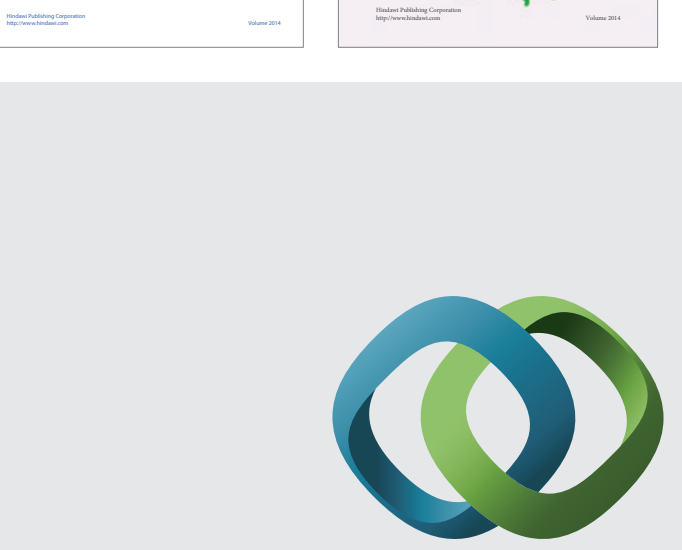

\section{Hindawi}

Submit your manuscripts at

http://www.hindawi.com
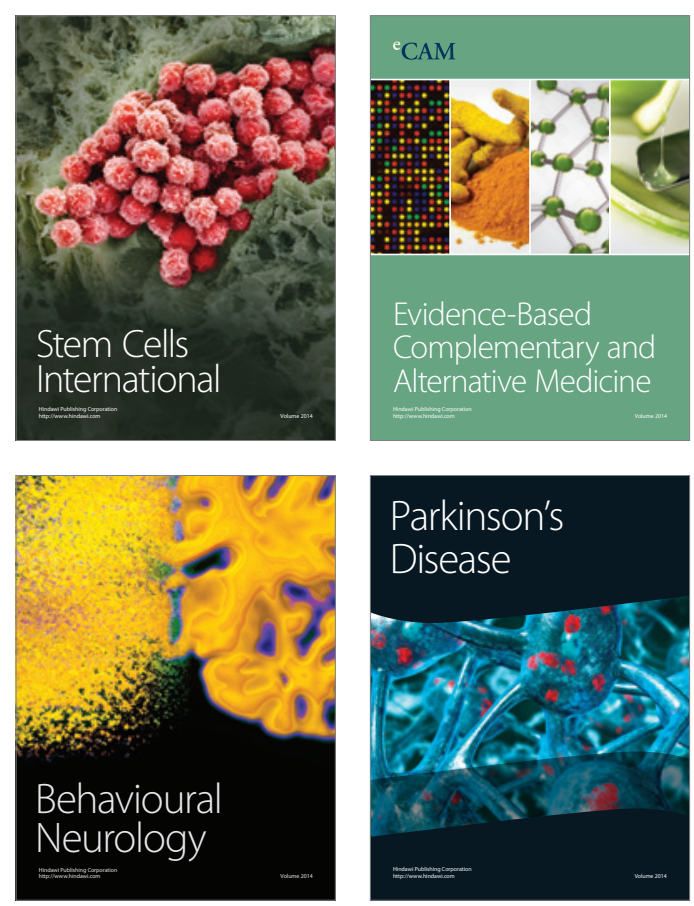

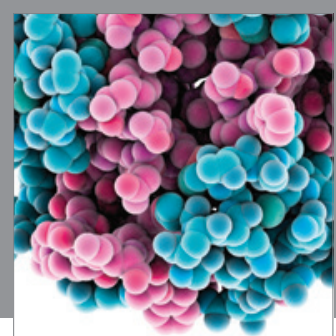

Journal of
Diabetes Research

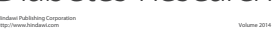

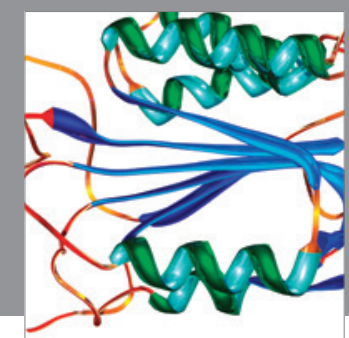

Disease Markers
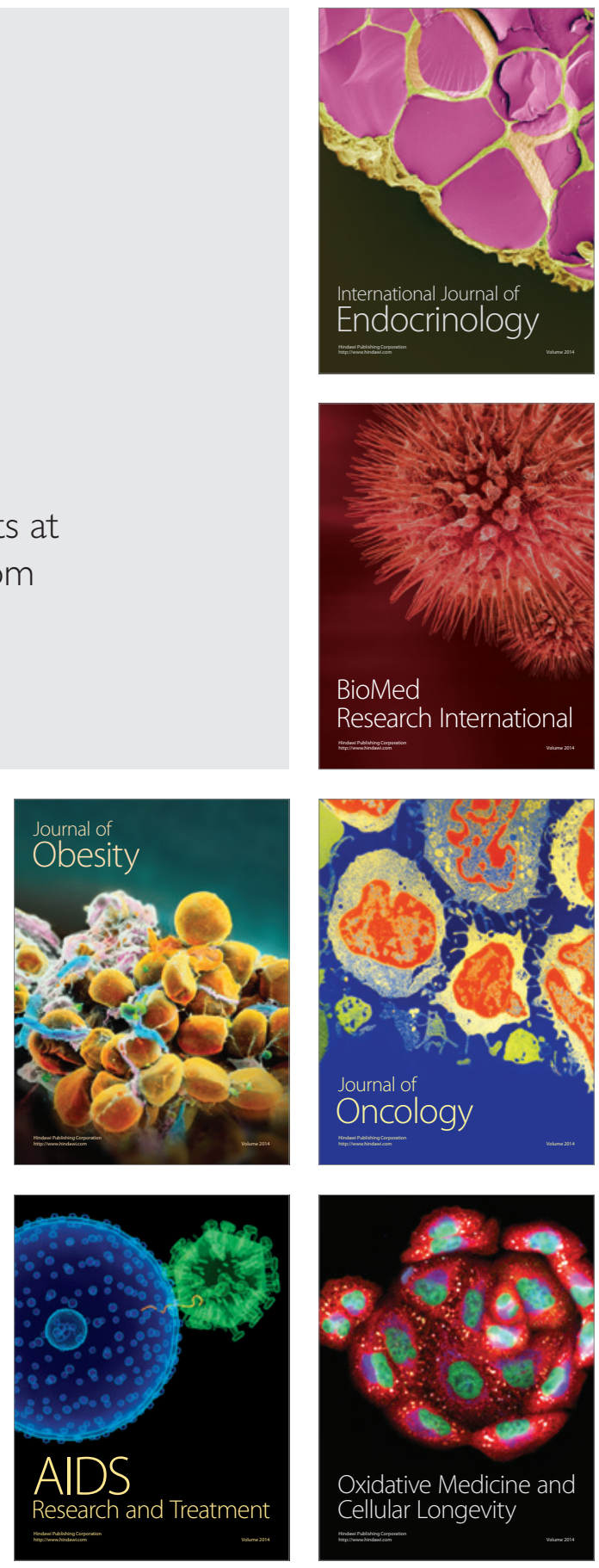